\title{
Evaluation of experimental designs in durum wheat trials
}

\author{
Anastasios Katsileros $^{1}$ and Christos Koukouvinos ${ }^{2}$ \\ ${ }^{1}$ Faculty of Crop Science, Laboratory of Plant Breeding and Biometry, Agricultural University \\ of Athens, 11855, Athens, Greece \\ ${ }^{2}$ Department of Mathematics, National Technical University of Athens, Zografou 15773, \\ Athens, Greece, e-mail: ckoukouv@math.ntua.gr
}

\begin{abstract}
SUMMARY
Variability among experimental plots may be a relevant problem in field genotype experiments, especially when a large number of entries are involved. Four field trials on 24 durum wheat genotypes were conducted in 2013/14 in order to evaluate the efficiency of Incomplete Block, Alpha and Augmented designs in comparison with the traditional Randomized Complete Block Design (RCBD). The results showed that the RCBD can be replaced by an Alpha design, which provides better control of variability among the experimental units when the number of treatments to be tested in an experiment exceeds twenty. The ranking of the genotypes across the four designs was not constant.
\end{abstract}

Key words: Alpha design, Incomplete Block design, Augmented design, Relative Efficiency.

\section{Introduction}

Field trial design plays a crucial role in the efficiency of plant breeding programs. The experimental field that breeders use is a heterogeneous environment, mainly due to soil heterogeneity. Soil heterogeneity is a significant source of variance and affects the correct evaluation of treatmentsgenotypes because of the increased experimental error (Gomez and Gomez, 1984).

Traditional designs, such as the Randomized Complete Block Design (RCBD), attempt to reduce the effect of soil heterogeneity by increasing variability among blocks and minimizing variability within blocks. In this 
design treatments must be arranged all together in each group, but the number of treatments usually cannot exceed 20 , because heterogeneity increases within the block and consequently experimental error increases too (Stroup et al., 1994; Stringer et al., 2012). To overcome this problem, a new category of designs has been developed with each group divided into smaller more homogeneous subgroups that do not contain all treatments. These designs are called Incomplete Block designs (IBD). The first designs of IBD type were Lattice and Balanced-IBD (Yates, 1936). In these designs every pair of treatments is placed together in a group the same number of times, and as a result all comparisons of treatment effects are made with the same precision.

Although Lattice and Balanced-IBD designs were developed for large numbers of treatments, they require many replications in order to be effective. Partially Balanced Incomplete Block designs (PBIB) offer greater freedom of choice in the number of replications (Bose and Nair, 1939). An improved version of PBIB designs is Alpha designs, which are created with the use of circular procedures. Alpha designs prove to be particularly useful thanks to their flexibility in handling any number of genotypes in any number of replications and still being able to have incomplete groups of various sizes (Patterson and Williams, 1976). A modification of Alpha designs is Latinized row-column designs (Williams and John, 1989).

Augmented designs have been developed for the evaluation of genotypes in the early stages of a breeding program, when the genetic material is limited and replications cannot be made (Federer, 1956). Control treatments are used in these designs with replications in check plots, in order to evaluate the genetic material with no replications. More sophisticated Augmented designs allow for the adjustment of test varieties by rows and columns (Federer and Raghavarao, 1975; Lin and Poushinsky, 1983). In these designs, each test variety is surrounded by two, three, or four check plots.

The aim of this study is to evaluate simultaneously, in the same environment, three experimental designs in comparison with a randomized complete block design, which is the most traditional method for controlling 
heterogeneity in field experiments. Moreover, information will be collected concerning the most suitable design for the evaluation of field experiments in breeding programs under the conditions of the Mediterranean zone.

\section{Materials and methods}

The experiments took place at the experimental station of the Agricultural University of Athens, in the area of Copais, in the growing season 2013/2014. Four experimental designs were evaluated: RCBD, IBD, Augmented design and Alpha design (Table 1). A total of 24 varieties of durum wheat were used, with four extra varieties in the Augmented design as check plots (Table 2).

Table 1. Coding of varieties

\begin{tabular}{cccc}
\hline Code & Variety & Code & Variety \\
\hline 0. & ATHOS & 14. & EKAVI \\
1. & AIAS & 15. & KARPASIA \\
2. & ANNA & 16. & KIPEROUNTA \\
3. & KALLITHEA & 17. & MAKEDONIA \\
4. & MEXICALI & 18. & MESAORIA \\
5. & PAPADAKIS & 19. & URANIA \\
6. & PONTOS & 20. & ATLAS \\
7. & SIFNOS & 21. & CLAUDIO \\
8. & SKITI & 22. & CORE \\
9. & SKIROS & 23. & DUILIO \\
10. & PIETRAFITTA & -1. & IRIDE * \\
11. & QUADRATTO & -2. & MATT * \\
12. & LIMNOS & -3. & SVEVO * \\
13. & ARONAS & -4. & WAHA * \\
\hline \multicolumn{4}{c}{ check plots for Augmented design }
\end{tabular}

Table 2. Size of experimental designs

\begin{tabular}{cccccc}
\hline Design & Treatments & Blocks & Plots & Rep. & Runs \\
\hline RCBD & 24 & 3 & 24 & & 72 \\
IBD & 24 & 3 & 16 & & 48 \\
ALPHA & 24 & 4 & 6 & 2 & 48 \\
AUGM. & $24+4$ & 4 & 10 & & 40 \\
\hline
\end{tabular}


The experimental plots consisted of four two-meter-long rows, spaced 20 $\mathrm{cm}$ apart. Plants were harvested and the final yield was estimated in grams per square meter.

The experiments were designed with CropStat 7 (2007) and Gendex DOE Toolkit (2015) software. The experiment with randomized complete blocks was conducted in three blocks (Fig. 1), the experiment with incomplete blocks in three blocks, each containing 16 experimental plots (Fig. 2), the experiment with the Alpha design in four blocks, each containing six experimental plots, with two replications (Fig. 3), and the experiment with the Augmented design in four blocks containing ten experimental plots with four control varieties (Fig. $4)$.

The linear model of observations in the Randomized Complete Block, Incomplete Block and Augmented designs is of the form:

$$
\mathrm{Y}_{\mathrm{ij}}=\mu+\tau_{\mathrm{i}}+\alpha_{\mathrm{j}}+\varepsilon_{\mathrm{ij}},
$$

where $Y_{i j}$ denotes the value of the observed yield for the $i$ th treatment obtained in the $j$ th block, $\mu$ is the grand mean, $\tau_{\mathrm{i}}$ is the effect of the $i$ th treatment, $\alpha_{\mathrm{j}}$ is the effect of the $j$ th block, and $\varepsilon_{\mathrm{ij}}$ is a random error.

The linear model of observations in the Alpha design is of the form:

$$
Y_{i j k}=\mu+\tau_{i}+\rho_{j}+\alpha_{j k}+\varepsilon_{i j k}
$$

where $Y_{i j k}$ denotes the value of the observed trait for the $i$ th treatment obtained in the $k$ th block within the $j$ th replicate, $\mu$ is the grand mean, $\tau_{\mathrm{i}}$ is the effect of the $i$ th treatment, $\rho_{j}$ is the effect of the $j$ th replicate, $\alpha_{\mathrm{jk}}$ is the effect of the $k$ th incomplete block within the $j$ th replicate, and $\varepsilon_{i j}$ is a random error. The statistical analysis for the Alpha design was performed using the following order: Treatment + Rep + Rep/Block(Random)

The mean square error from each analysis was used to estimate the relative efficiency of a design compared with an RCBD, according to the following equation:

$$
\text { Relative Efficiency }=\frac{\text { Mean Square Error in RCBD }}{\text { Mean Square Error in other Design }} * 100
$$




\begin{tabular}{c|c|c|c|c|c|c|c|c|c|c|c|c|} 
III & 20 & 4 & 22 & 7 & 10 & 17 & 16 & 8 & 13 & 5 & 3 & 21 \\
\cline { 2 - 12 } II & 14 & 15 & 13 & 12 & 11 & 17 & 4 & 23 & 22 & 9 & 7 & 3 \\
\cline { 2 - 11 } I & 0 & 1 & 2 & 3 & 4 & 5 & 6 & 7 & 8 & 9 & 10 & 11 \\
\hline
\end{tabular}

\begin{tabular}{c|c|c|c|c|c|c|c|c|c|c|c|c|}
\cline { 2 - 11 } III & 6 & 23 & 11 & 12 & 9 & 0 & 18 & 14 & 2 & 1 & 19 & 15 \\
\cline { 2 - 11 } II & 0 & 18 & 21 & 19 & 16 & 2 & 10 & 6 & 5 & 20 & 1 & 8 \\
\cline { 2 - 12 } I & 12 & 13 & 14 & 15 & 16 & 17 & 18 & 19 & 20 & 21 & 22 & 23 \\
\hline
\end{tabular}

Figure 1. Layout of the Randomized Complete Block Design

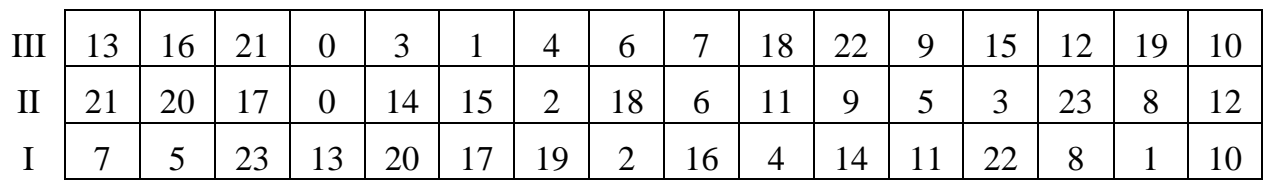

Figure 2. Layout of the Incomplete Block design

\begin{tabular}{|c|c|c|c|c|c|c|c|c|c|c|c|c|c|}
\hline IV & 14 & 20 & 1 & 17 & 6 & 11 & \multirow{2}{*}{$\begin{array}{l}\text { IV } \\
\text { III } \\
\text { I }\end{array}$} & 7 & 12 & 1 & 16 & 23 & 9 \\
\hline III & 9 & 3 & 19 & 4 & 22 & 12 & & 5 & 11 & 14 & 18 & 21 & 3 \\
\hline II & 13 & 10 & 0 & 16 & 23 & 5 & II & 22 & 15 & 6 & 19 & 0 & 8 \\
\hline I & 18 & 8 & 21 & 2 & 7 & 15 & I & 10 & 2 & 20 & 4 & 13 & 17 \\
\hline
\end{tabular}

Figure 3. Layout of the Alpha design

\begin{tabular}{|c|c|c|c|c|c|c|c|c|c|c|}
\hline IV & 21 & 7 & 11 & -2 & -1 & -4 & 13 & -3 & 15 & 4 \\
\hline III & 8 & -3 & 0 & -2 & 19 & 2 & 16 & -4 & 18 & -1 \\
\hline II & 1 & -4 & 10 & 20 & -3 & 23 & 5 & 9 & -2 & -1 \\
\hline I & -1 & 17 & 22 & 3 & 12 & -2 & 6 & -4 & -3 & 1 \\
\hline
\end{tabular}

Figure 4. Layout of the Augmented design 
An estimated relative efficiency less than $100 \%$ indicates that the RCBD is a more efficient design, while a value greater than $100 \%$ suggests that the other design is a more efficient design than the RCBD.

The models were compared in terms of the coefficient of determination $\left(\mathrm{R}^{2}\right)$, the adjusted coefficient of determination $\left(\mathrm{R}^{2}{ }_{\mathrm{adj}}\right)$, the residual standard deviation (SD), the coefficient of variation (CV\%), and the Akaike Information Criterion (AIC) (Akaike 1974). The above estimations were obtained using R software (2014).

\section{Results and discussion}

Analysis of variance for the RCBD (Table 3) showed that effects of both varieties $(\mathrm{p}<0.001)$ and blocks $(\mathrm{p}<0.001)$ were statistically significant. The coefficient of determination $\left(\mathrm{R}^{2}\right)$ was 0.79 , the adjusted coefficient of determination was 0.68 , the coefficient of variation 16.0 and the AIC criterion 798.3. Analysis of variance for the IBD also showed significant effects of varieties $(\mathrm{p}<0.001)$ and blocks $(\mathrm{p}=0.0096)$. The coefficient of determination $\left(R^{2}\right)$ was 0.87 , the adjusted coefficient of determination was 0.72 , the coefficient of variation 13.25 and the AIC criterion 564.4. Analysis of variance for the Alpha design showed that the effect of varieties $(\mathrm{p}=0.0033)$ was statistically significant. The coefficient of determination $\left(R^{2}\right)$ was 0.90 , the adjusted coefficient of determination was 0.80 ,

Table 3. Summary of the fit of experimental designs

\begin{tabular}{lcccc}
\hline & RCBD & IBD & ALPHA & AUGM \\
\hline $\mathrm{R}^{2}$ & 0.79 & 0.87 & 0.90 & 0.93 \\
$\mathrm{R}^{2}$ Adj & 0.68 & 0.72 & 0.80 & 0.71 \\
S.D. & 39.37 & 33.15 & 26.76 & 34.61 \\
CV \% & 16.00 & 13.25 & 10.50 & 12.76 \\
AICc & 789.3 & 564.4 & 560.3 & 703.1 \\
R.E. \% & $100 \%$ & $118.7 \%$ & $147.1 \%$ & $113.7 \%$ \\
Mean $\left(\mathrm{g} \mathrm{m}^{-2}\right)$ & 246.0 & 250.2 & 254.9 & 271.2 \\
$\mathrm{~N}$ & 72 & 48 & 48 & 40 \\
\hline
\end{tabular}


the coefficient of variation 10.50 and the AIC criterion 560.3. Analysis of variance for the Augmented design showed that the effect of varieties ( $\mathrm{p}=0.0180$ ) was statistically significant, but the effect of blocks ( $\mathrm{p}=0.0942)$ was not. The coefficient of determination $\left(\mathrm{R}^{2}\right)$ was 0.93 , the adjusted coefficient of determination was 0.71 , the coefficient of variation 12.76 and the AIC criterion 703.1.

Comparing the four experimental designs, we observed that the highest percentage of variance is explained by the Augmented design (93\%), followed by the Alpha design (90\%). The Alpha design nevertheless has the largest adjusted coefficient of determination $(80 \%)$, the lowest coefficient of variance (10.5\%), the smallest value of the AIC criterion (560.3) and the highest relative efficiency (147\%). Regarding the final ranking of varieties with regard to the final yield (Table 4), the elite varieties 21 and 23 appear in almost all the designs. Variety 23 is absent from the Augmented design, with variety 15 taking its place. In the intermediate positions there is great differentiation in the ranking of the varieties, although the results for the three lowest-yielding varieties are similar.

It should be noted that the ranking of varieties based on the mean yield (Table 4) needs to be treated with caution. Only the estimates of mean yields obtained for RCBD have a certain statistical interpretation and are unique. Other "estimates" (so-called adjusted means) depend on the algorithm used to solve the singular normal equations associated with estimating model parameters.

\section{Conclusion}

This study has shown that significant improvements can be achieved in controlling variability by using alternative designs when a large number of entries are involved. From the statistical analysis of the yield data from all of the experiments, it appears that using the traditional RCBD does not improve the experimental accuracy of the experiments, since it was less effective than the other designs. The Alpha design produces better results in comparison with 
Table 4. Ranking of the varieties and the mean yield $\left(\mathrm{g} \mathrm{m}^{-2}\right)$

\begin{tabular}{ccccccccc}
\hline & \multicolumn{2}{c}{ RCBD } & \multicolumn{2}{c}{ IBD } & \multicolumn{2}{c}{ ALPHA } & \multicolumn{2}{c}{ AUGM. } \\
Ranking & Variety & Yield & Variety & Yield & Variety & Yield & Variety & Yield \\
\hline 1 & 23 & 342.7 & 21 & 344.3 & 23 & 358.0 & 21 & 382.9 \\
2 & 21 & 332.3 & 23 & 342.9 & 21 & 342.1 & 15 & 360.9 \\
3 & 17 & 308.3 & 15 & 310.8 & 15 & 325.3 & 4 & 352.9 \\
4 & 5 & 307.0 & 4 & 306.3 & 17 & 319.2 & 23 & 347.6 \\
5 & 4 & 305.3 & 17 & 304.4 & 5 & 313.8 & 17 & 307.6 \\
6 & 15 & 300.3 & 5 & 298.9 & 1 & 286.2 & 13 & 302.9 \\
7 & 14 & 284.7 & 10 & 277.3 & 10 & 283.6 & 7 & 285.9 \\
8 & 1 & 271.7 & 1 & 272.3 & 20 & 282.7 & 14 & 270.6 \\
9 & 13 & 271.3 & 9 & 270.3 & 14 & 280.4 & 5 & 260.6 \\
10 & 10 & 261.3 & 14 & 259.9 & 13 & 275.6 & 11 & 255.9 \\
11 & 9 & 260.0 & 13 & 259.8 & 9 & 265.2 & 19 & 253.9 \\
12 & 20 & 254.0 & 7 & 253.8 & 4 & 260.7 & 1 & 249.6 \\
13 & 22 & 249.3 & 20 & 252.9 & 19 & 250.2 & 10 & 249.6 \\
14 & 7 & 245.7 & 12 & 244.3 & 12 & 246.2 & 20 & 248.6 \\
15 & 19 & 241.7 & 6 & 241.3 & 7 & 242.8 & 9 & 242.6 \\
16 & 2 & 224.7 & 19 & 241.3 & 2 & 238.8 & 22 & 241.6 \\
17 & 12 & 222.0 & 22 & 229.3 & 8 & 237.3 & 2 & 233.9 \\
18 & 11 & 216.3 & 2 & 223.9 & 6 & 231.7 & 6 & 214.6 \\
19 & 6 & 210.0 & 0 & 216.3 & 22 & 223.2 & 12 & 213.6 \\
20 & 8 & 205.7 & 8 & 202.9 & 11 & 215.9 & 8 & 211.9 \\
21 & 0 & 189.3 & 11 & 201.4 & 0 & 191.5 & 0 & 199.9 \\
22 & 3 & 154.7 & 3 & 170.8 & 3 & 173.5 & 3 & 151.6 \\
23 & 18 & 123.7 & 18 & 143.8 & 18 & 137.1 & 16 & 143.9 \\
24 & 16 & 123.0 & 16 & 136.8 & 16 & 137.0 & 18 & 129.9 \\
\hline & & & & & & & &
\end{tabular}

the other designs in the evaluation of 24 durum wheat varieties. These results are in agreement with those obtained by Yau (1997), Masood et al. (2008), Abd El-Shafi (2014) and Khan et al. (2015). The major advantage of the experimental designs used is the smaller total number of experimental plots with respect to the classic design of randomized complete blocks. This is particularly helpful in achieving better management of the experiments. 
Finally, the conclusion drawn from this study that the use of an Alpha design can improve the precision of wheat performance trials may be of value to wheat breeders in Mediterranean conditions.

\section{Acknowledgements}

The authors thank the editor and referees for their comments and suggestions that resulted in improvement of the quality of presentation of the present manuscript.

\section{REFERENCES}

Abd El-Shafi M.A. (2014): Efficiency of classical complete and incomplete block designs in yield trial on bread wheat genotypes. Research Journal of Agriculture and Biological Sciences 10(1): 17-23.

Akaike H. (1974): A new look at the statistical model identification. IEEE Transactions on Automatic Control 19: 716-723.

Bose R.C., Nair K.R. (1939): Partially balanced incomplete block designs. Sankhya 4: 337-372.

CropStat for Windows ver.7.2 (2007): International Rice Research Institute.

Federer W.T. (1956): Augmented (or Hoonuiaku) designs. The Hawaiian Planters' Record. LV(2): 191-208.

Federer W.T., Raghavarao D. (1975): On augmented designs. Biometrics 31: 29-35.

Gendex (2015): Gendex DOE Toolkit. http://designcomputing.net/gendex/

Gomez, K.A., Gomez A.A. (1984): Statistical Procedures for Agricultural Research, 2nd ed. Wiley, New York.

Khan, M.I., Ali Shah S.A., Khan M., Ullah K., Ullah R., Khatak S.I. (2015): Comparative efficiency of alpha lattice design and complete randomized block design in wheat, maize and potato field trials. Journal of Resources Development and Management 11: 115-117.

Lin, C.S., Poushinsky G. (1983): A modified augmented design for an early stage of plant selection involving a large number of test lines without replication. Biometrics 39: 553-561.

Masood, M.A., Farooq K., Mujahid Y., Anwar M.Z. (2008): Improvement in precision of agricultural field experiments through design and analysis. Pakistan Journal of Life and Social Science 6: 89-91.

Patterson, H., Williams E.R. (1976): A new class of resolvable incomplete block designs. Biometrika 63: 83-92.

R Core Team (2014): R: A language and environment for statistical computing. $\mathrm{R}$ Foundation for Statistical Computing, Vienna, Austria. URL http://www.Rproject.org/. 
Stringer J.K., Smith A.B., Cullis B.R. (2012): Spatial analysis of agricultural field experiments. In: K. Hinkelmann (Ed.), Design and analysis of experiments, Vol 3, Special designs and applications: 109-136.

Stroup W.W., Baenzinger P.S., Mulitze D.K. (1994): Removing spatial variation from wheat yield trials: a comparison of methods. Crop Science 86: 62-66.

Williams, E.R., John J.A. (1989): Construction of row and column designs with contiguous replicates. Applied Statistics 38: 149-154.

Yates, F. (1936): A new method of arranging variety trials involving a large number of varieties. Journal of Agricultural Science 26: 424-455.

Yau, S.K. (1997): Efficiency of alpha-lattice designs in international variety yield trials of barley and wheat. Journal of Agricultural Science, Cambridge 128: 5-9. 